\title{
Regulation and the Management of Expectations- Rating Agencies Revisited
}

\author{
Markus Hinterleitner ${ }^{\mathrm{A}}$ \& Christian Rosser $^{\mathrm{B}}$
}

In the aftermath of the 2008 crisis, scholars have begun to revise their conceptions of how market participants interact. While the traditional "rationalist optic" posits market participants who are able to process decisionrelevant information and thereby transform uncertainty into quantifiable risks, the increasingly popular "sociological optic" stresses the role of uncertainty in expectation formation and social conventions for creating confidence in markets. Applications of the sociological optic to concrete regulatory problems are still limited. By subjecting both optics to the same regulatory problem-the role of credit rating agencies (CRAs) and their ratings in capital markets-this paper provides insights into whether the sociological optic offers advice to tackle concrete regulatory problems and discusses the potential of the sociological optic in complementing the rationalist optic. The empirical application suggests that the sociological optic is not only able to improve our understanding of the role of CRAs and their ratings, but also to provide solutions complementary to those posited by the rationalist optic.

Keywords: expectations, regulation, risk, sociological optic, uncertainty

\section{Introduction}

$\mathrm{R}$

egulatory approaches and principles of economic and financial been questioned in the wake of the 2008 crisis (Tonkiss 2009; Amable et al. 2010; Lodge and Wegrich 2010; Vibert 2011; Baker 2013; Black 2013a; 2013b; Beckert 2013; Nelson and Katzenstein 2014). The diverse body of the literature shares the insight that the crisis has exposed vari- ous shortcomings pertaining to the design of regulatory market interventions. Although, it is still contested whether the crisis will lead to the emergence of a new regulatory paradigm (Levi-Faur and Parker 2010; Vogel 2010; Baker 2013), scholars have begun to revise their conceptions of how market actors interact (Black 2013a) and many innovative ideas have (re)entered the scientific discourse in recent years. An important strand of ideas has developed around a "sociological optic"

\footnotetext{
${ }^{\text {A }}$ Center of Competence for Public Management, University of Bern, Switzerland

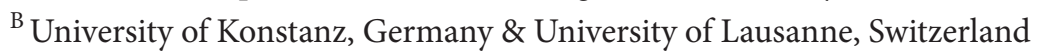


of market action which counters the more traditional "rationalist optic" (Nelson and Katzenstein 2014). While the rationalist optic posits market participants who can process decision-relevant information and thereby transform uncertainty into quantifiable risks, the sociological optic assumes that uncertainties cannot be readily transformed into risks. Instead, the sociological optic claims that conventions and social relations are needed to stabilize the expectations of market participants made under uncertainty and to thereby create confidence in markets.

While the sociological optic has been discussed from a theoretical perspective, applications to concrete regulatory problems are still limited. The present paper aims to contribute to filling this gap. By subjecting the sociological and the rationalist optic to the same empirical problem - the role of credit rating agencies (CRAs) and their ratings in global capital markets-we attempt to provide insights into whether the sociological optic offers practical advice to tackle actual regulatory problems and whether the solutions suggested by the sociological optic complement those suggested by the rationalist optic. The present paper thus stands in line with George and Bennett (2005, chapter 12), who call for more transformation of scientific knowledge into policy applicable knowledge.

The paper proceeds as follows: using social learning theory (Hall 1993), we first illustrate that the rationalist optic developed as a consequence of the paradigmatic shift from the Keynesian welfare state to the regulatory state. Discussing implications of this shift, we then demonstrate how the rationalist optic translates into a regulatory toolbox that has trouble addressing cases of market failure where uncertainty undermines confidence between market participants. Subsequently, we illustrate that, in contrast to the rationalist optic, the sociological optic pays particular attention to the impact of uncertainty on the expectation formation of market participants. We then outline the contours of a regulatory approach that engages with the development of confidence between market participants by stabilizing their expectations formed under uncertainty. In the empirical part, we subject both optics to the same regulatory problem, namely the role of CRAs and their ratings in global capital markets. The role of CRAs in capital markets and the consequences that emanate from their decision-making represent a tricky regulatory problem for which encompassing solutions are hard to find. Our empirical application suggests that the sociological optic is not only able to improve our understanding of the role of CRAs and their ratings, but also to provide solutions that are complementary to those posited by the rationalist optic.

\section{The Paradigmatic Shift from the Keynesian Welfare State to the Regulatory State}

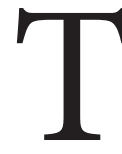
The regulatory state is commonly conceived as successor to the Keynesian welfare state (Majone 1997; Yeung 2010). Whereas the welfare state redistributes, engages in macroeconomic stabilization and deficit spending, the regulatory state concentrates on correcting market failures and making rules (Majone 1997, 149). Even if a strict distinction between welfare and regulatory state may be challenged (Levi-Faur 2011; Braithwaite 2008, 4-12), the distinction 
still clarifies that the shift in the understanding of the state has not only been caused by factual necessities, but also by a conceptual reinterpretation of the capitalist system.

The fundamental difference between the Keynesian welfare state and the regulatory state can be explained by recurring to the idea of policy paradigm shifts (Hall 1993). This approach stresses the role of ideas in policymaking by studying the process of social learning. Hall (1993) defines social learning as "a deliberate attempt to adjust the goals or techniques of policy in response to past experience and new information" (278). The centrality of ideas in social learning stems from the assumption that "policymakers customarily work within a framework of ideas and standards that specifies not only the goals of policy and the kind of instruments that can be used to attain them, but also the very nature of the problems they are meant to be addressing" (Hall 1993, 279). These "policy paradigms" hold together and explain the specific configurations of three variables: policy goals, policy instruments, and specific settings of instruments. When not only the applied instruments and their settings, but also policy goals change, a paradigm shift occurs.

The shift from the Keynesian welfare state to the regulatory state represents such a paradigm shift (Hall 1993,
284). While the state's creative power and ability to steer the economy had enjoyed widespread public confidence until the 1970s, skepticism toward the state's capacity in stabilizing the economy subsequently grew across nearly all political colors. Negative consequences of resource-consuming state interventions, like rising sovereign debts or inefficient market interventions, threatened the Keynesian paradigm, which found one of its fiercest critics in the theory of neoliberalism (Castles et al. 2010).

Fundamental to this paradigmatic shift is a particular idea of how market dynamics and policy choices are framed-an idea that Nelson and Katzenstein $(2014,364)$ call "rationalist optic." This optic accords a prominent role to markets and their self-regulating capabilities, implying a state that "governs at a distance" (Yeung 2010). Emblematic of the rationalist optic's trust in the allocating powers of markets is the efficient market hypothesis (EMH), which has come to dominate large parts of economic regulation (Moloney 2010; Baker 2013; Black 2013a). In general, the EMH asserts that markets can operate on a basis where prices reflect all available information (Fama 1970). Market failure can thus occur only when prices do not reflect the intrinsic value of a traded product, and consequently, market participants do not dispose of sufficient information to make

\footnotetext{
${ }^{1}$ An example for this kind of market failure is Akerlof's (1970) “market for lemons," where dishonest car sellers drive out the honest sellers leaving only bad cars (lemons) for sale. Since information about the true quality of cars is distributed asymmetrically between sellers and buyers, the latter will rationally pay a maximum price equal to the average price of all cars on offer. This brings sellers of cars with intrinsic value above the average price to exit the market, leaving behind a "market for lemons." Insufficient information about the quality of products on the side of potential buyers thus leads to market failure.
} 
well-informed, rational decisions ${ }^{1}$. The rationalist idea of markets and explanations for their failure translate into a specific design and application of regulatory interventions, which will be discussed in the next section.

\section{Comparing the Rationalist and the Sociological Optic from a The- oretical Perspective}

$\mathrm{T}$

The rationalist optic assumes that rational market participants can transform uncertainties into calculable risks if they dispose of sufficient information (Hutter 2010). By improving "the availability of information" (OECD 2008, 6), regulatory interventions intend that prices better reflect the intrinsic value of a product and that risks can be accurately incorporated into prices. Emphasis is thus put on regulatory interventions that "complete" a market by improving the information available to market participants. This can be achieved, for instance, by taxing a product in a way that reflects the fundamental value of the product (OECD 2008) or by enforcing forms of mandatory disclosure (Moloney 2010). These examples highlight an important rationale for regulatory interventions based on a rationalist optic, namely that the market can be completed by providing information. In other words, a rationalist optic assumes that it is sufficient to remove information constraints to improve market functioning.

When the rationalist optic does not equate uncertainty with risk (Nelson and Katzenstein 2014, 365), it takes uncertainty to be policy induced. Uncertainty is then regarded as an undesired "side effect" that is unintentionally but actively created by regulatory interventions. Scholars have discussed the potential impact of policy-induced uncertainty on economic growth, investment, and employment (Julio and Yook 2012; Baker et al. 2013). "Regulatory" uncertainty' caused by regulatory interventions in the aftermath of crisis and its potential influence on growth and job creation also figure in contemporary work (e.g. Battalio and Schultz 2011; Kingsley et al. 2012). What the rationalist optic assumes is that, in principle, policy-induced uncertainty can be reduced by providing sophisticated regulatory interventions.

The sociological optic criticizes regulatory interventions based on a rationalist optic for neglecting cases of market failure where confidence between market participants is undermined by uncertainty. Given the limited capabilities of market participants to process decision-relevant information in complex information environments, market action can be significantly and enduringly distorted (Blyth 2006; Beckert 2013). The financial system, in particular, has become too complex to allow for unproblematic information processing (Best 2010). According to the sociological optic, uncertainty in decision making is far more important and widespread than the rationalist optic and its efficient market understanding would assume (March 1994; Nelson and Katzenstein 2014).

Borrowing from the Keynesian paradigm, the sociological optic claims that uncertainty has a significant impact on expectation formation and the subsequent behavior of market participants (Dequech 2006; Beckert 2013). The latter base their decisions on expectations regarding future outcomes and, depending on the decision-making situation, they 
can (or cannot) determine potential outcomes or even the probability that such outcomes occur. Accordingly, rational expectations based on informed calculations can often not be formed. Instead, actors are compelled to make decisions and arrange themselves with the unpredictability of some future events (Nelson and Katzenstein 2014, 366). To put it in Keynes' (1937) words, sometimes "there is no scientific basis on which to form any calculable probability whatever. We simply do not know" (213-214).

In a state of uncertainty ${ }^{2}$, expectations are thus not "determined through calculation of optimal choices taking into account all available information, but rather are based on contingent interpretations of the situation in the context of prevailing institutional structures, cultural templates, and social networks" (Beckert 2013, 325). The Keynesian paradigm acknowledges that sudden and unexpected events can lead to uncertainty, which unsettles market participants and thereby influences their expectations and their disposition to invest or consume (Keynes 1936, 316). The Keynesian solution to reverse this suboptimal situation is to manage uncertainty via governmental interventions which aim to stabilize the expectations of market participants and restore confidence in markets.

There are at least four areas where the expectation formation of market participants under uncertainty is constitutive for the expansive dynamics of capitalist systems and can thus be targeted by governmental interventions (Sewell 2008;
Beckert 2013, 327-340). First, in order to expand, markets depend on creativity. Creativity can only be transformed into concrete innovations if market participants develop concrete "imaginaries" of the future. Only in environments, where market participants are encouraged to believe that innovation development is rewarded, growth-enhancing new products and services can be developed. Second, modern capitalist systems are credit-driven and therefore rely on the development of confidence between borrowers and creditors. Therefore, markets must "succeed in creating the expectation in capital owners that the promise entailed in the credit relation will indeed be honored" (Beckert 2013, 332). Third, commodification describes the transformation of goods into tradable products. For goods to be tradable, they must contain a (symbolic) value for potential buyers. The value relies on personal expectations regarding the future performance of the good. Fourth, markets are driven by the competition for profit opportunities. This leads to the questions of "how expectations regarding opportunities for profit are created in competitive markets" (Beckert $2013,339)$ and how a fair competition environment can be secured.

In these four areas of capitalist systems, individual expectation formation under uncertainty plays a major role. The release of innovation, confidence for credit relations, value assignments, and expected profit opportunities cannot be understood without considering expectation formation under uncertainty. Ac-

\footnotetext{
${ }^{2}$ Note that the Keynesian understanding of uncertainty is different from Frank Knight's (2006 [1921]) conception of the term (Best 2008). Keynes deduces a specific logic of governmental intervention from his understanding of uncertainty, which is of central relevance here.
} 
cordingly, influencing "the decisions of actors by shaping their expectations, including the shaping of the social and political structures underlying these expectations, becomes one of the main tasks of political regulators" (Beckert 2013, 326). Social conventions, understood as shared understandings that organize and coordinate actions, deserve particular attention, since they help to predict behavior and thereby stabilize uncertain environments (Biggart and Beamish 2003; Nelson and Katzenstein 2014). Following the sociological optic, regulatory interventions should not solely focus on the management of various kinds of risks, but also proactively target uncertainty in (1) innovation development, (2) credit relations, (3) value assignments, and (4) profit opportunities. For this purpose, regulators need to elicit where market participants' expectations are susceptible to uncertainties, and if possible, stimulate the formation of structures and conventions which are able to stabilize these uncertainties ${ }^{3}$.

While the sociological optic has been discussed from a theoretical perspective, it has rarely been applied to concrete regulatory problems. Moreover, it is not yet clear whether the sociological and the rationalist optic suggest solutions to regulatory problems that can be fruitfully combined. In what follows, we discuss the problematic role of CRAs and their decision making from both a rationalist and a sociological perspective in order to address this research gap.

\section{Applying the Rationalist and the Sociological Optic to the Case of Credit Rating Agencies}

The case of CRAs has been chosen
because of its theoretical prom-
inence in the literature. In fact, the area in which confidence has been most affected by the 2008 crisis is that of credit relations (Trampusch 2013). In the aftermath of the crisis, CRAs have been exposed to heavy criticism, with some seeing the current practice of credit rating as a primary cause of the crisis (Partnoy 2009). Criticism frequently pertains to the poor quality of ratings, the opacity surrounding rating decisions, conflict of interest, and the lack of competition between CRAs (Eijffinger 2012). However, comprehensively reforming the current practice of credit rating has so far proven elusive. It thus appears that the role of CRAs and their decision making represents a tricky regulatory problem. We, in the following, present the various problems associated with CRAs and their ratings, followed by a critical discussion of solutions posited by a rationalist optic. Finally, the problems with CRAs are analyzed through a sociological optic in order to establish whether it offers practical advice to address the outlined problems.

\footnotetext{
${ }^{3}$ Note that the sociological optic discussed here applies a somewhat different perspective on regulatory problems than macro-prudential regulation, which has also gained traction in recent years: While macroprudential regulation also rejects the efficient market hypothesis dominant in pre-crisis regulatory approaches, is concerned with systemic risk at the system level, and focuses on pro-cyclicality (Baker 2013), the sociological optic focuses on the impact of uncertainty on individual expectation formation at the micro-level.
} 
The role of CRAs and their ratings in global capital markets

CRAs are a particular kind of information providing intermediaries in financial markets. Traditionally, market participants were brought together by banks, which collected funds from creditors and lent these to adequate borrowers. In recent years, however, a process of "disintermediation" can be observed: "Depositors have found more attractive things to do with their money at the same time as borrowers have increasingly borrowed from nonbank sources" (Sinclair 2001, 444). In globalized capital markets, information about creditworthiness can no longer be provided by banks alone. Instead, they are flanked by CRAs, which issue "a corporate family-level opinion of the relative likelihood that any entity within a corporate family will default on one or more of its long-term debt obligations" (Moody's 2009, 18). Credit ratings have become an integral part of modern finance in both the United States and Europe, where bank-based coordinated market economies have substituted former non-market institutions by external rating practices (Carruthers and Kim 2011; Trampusch 2013).

Credit ratings are supposed to reduce uncertainties in decision making about credit (Carruthers 2013). CRAs assess and structure complex information, transform uncertainties into calculable risks and, as a consequence, provide single grades (complemented by rating watches and outlooks) indicating the risk of default. CRAs thus act as "institutional trust devices" (Beckert 2013) that help market participants build more adequate expectations about the financial and economic constitution of their trading part- ners. Theoretically, ratings are therefore considered as uncertainty-reducing devices that support confidence development between market participants, thereby stimulating the expansive dynamics on which capitalist systems rely.

However, during the recent crisis, CRAs failed across corporate families to adequately assess credit risk (Partnoy 2009). The rapid downgrades of top-rated products to junk status emphasized the fact that ratings did not make uncertainties more tractable. Instead of helping market participants form adequate expectations about credit risk, CRAs were unable to commodify credit risk in ways that properly depict contained uncertainties and risks. Consequently, CRAs did not act as institutional trust devices supporting confidence development between market participants.

In the face of this problem, the rationalist optic presumes that market participants invest in information to avoid systematic mistakes (Nelson and Katzenstein 2014). If information can be distributed among market participants, their expectations "about possible future states of the economy should converge and promote a stable and self-reinforcing equilibrium" (Blyth 2003, 243). From a rationalist point of view, the primary task of regulators is thus to ensure that CRAs provide correct and up-to-date information on rated entities. CRAs are thereby supposed to increase the transparency of the financial system so that information can be adequately incorporated into market prices. In this context, studies informed by a rationalist optic have suggested to target the lack of transparency of ratings, the lack of competition between CRAs, their problematic business model, and the regulatory use of ratings. 
The lack of transparency

Rating processes are frequently criticized for being insufficiently transparent and objective (Sinclair 1994; 2005; Bruner and Abdelal 2005; Iyengar 2010). It is claimed that more publicly available information about rating processes could enhance the understanding of final ratings and help market participants form better expectations about the creditworthiness of rated entities. Although CRAs usually publish so called "rating methodologies" or "guidelines"4 and explanations of specific rating decisions, these documents are very general and depend to a large degree on the personal opinions of the assessment teams (Sinclair 1994; Iyengar 2010). Moreover, neither do CRAs state the relative weighting of the factors relevant to the rating, nor can these factors always be quantified (Cantor and Packer 1996; Eijffinger 2012).

In reply to this criticism, CRAs underscore that their business model heavily depends on secrecy. They hold that more transparency would allow clients to influence rating decisions, thereby damaging the CRAs' highly valued reputation for neutrality. This argument contains some truth; more transparency would allow rated entities to "game the system" by applying strategies to get better ratings without ameliorating creditworthiness (Partnoy 2006; Róna-Tas and Hiß 2010).
Hence, "CRAs resist fiercely any attempts to make them more transparent" (Kerwer 2005, 469) 5 . Even if regulatory interventions could increase transparency by providing more information about rating procedures, market participants would not necessarily be able to incorporate all this information into their expectations. Large parts of the financial system have become too complex and the contained information too unclear to be both adequately depicted and correctly interpreted by market participants (Best 2010; Hu 2012). In a nutshell, a regulatory response aiming to increase the transparency of rating processes collides with a business model built on secrecy and cannot guarantee that market participants are able to use information on rating processes to enhance their understanding of final ratings.

\section{The lack of competition}

The current organization of credit rating is often criticized for its oligopolistic market structure dominated by the three major U.S. agencies (Standard \& Poor's, Moody's, and to a lesser extent Fitch Ratings). This lack of competition, it is argued, is responsible for a significant herd mentality between the agencies (Gaillard 2011) and poor rating quality. Greater competition could lead to improved ratings, since erroneous ratings would be "policed" by the market. This

\footnotetext{
${ }^{4}$ See for instance: http://www.standardandpoors.com/ratings/sovresearch/en/us (retrieved: August 1, 2015).

${ }^{5}$ It may alternatively be argued that the lack of transparency is generally overrated and, therefore, does not lie at the core of low-quality ratings. Not only did CRAs provide access to the rating methodology of some structured financial instruments. They also handed over their rating algorithms on CD to the issuers who could then tweak their products accordingly. Also, some investment banks hire CRA employees to inform them about the rating process.
} 
could reduce the overall likelihood of CRAs producing faulty ratings and make ratings more accurate in depicting uncertainties and risks.

However, as the difficulty to establish an influential European CRA suggests, market entry barriers for potential competitors are high (White 2002). In addition, competition cannot assume its "policing function" when there is a regulatory use of ratings. Regulators have gradually adopted credit ratings for regulatory purposes and the management of market risks. Not only are ratings used to define investment restrictions for financial institutions such as pension funds. They also serve to determine disclosure requirements and capital reserve requirements according to the presumed risk exposure of financial institutions (Pagano and Volpin 2010; White 2010; Carruthers and Kim 2011).

This regulatory use of ratings represents a significant market entry barrier for potential competitors, since not all ratings are deemed sound enough by regulators to provide an adequate estimate for credit risk. For instance, only credit ratings issued by CRAs that have been accorded the special status of nationally recognized statistical rating organizations by the U.S. Securities and Exchange Commission qualify for regulatory use. This creates an artificial demand for credit ratings issued by firmly established CRAs that is not conditional upon the actual quality of ratings. Therefore, "ratings no longer function as opinions to be taken or left by investors, and market discipline is accordingly sacrificed" (Bruner and Abdelal 2005, 202). Put differently, regulators have endowed CRAs with a legal authority that translates into an authoritativeness of ratings which is not conditional on the actual quality of ratings.

Another point that speaks against a beneficial effect of increased competition on the quality of ratings is the problematic "issuer pays" business model of current rating practices. Since CRAs get paid by the entities they are supposed to rate, they are subject to a conflict of interests, making objective rating more difficult (Bolton et al. 2012). Increased competition may thus increase the CRAs' eagerness to appease their customers by doling out generous ratings. In conclusion, providing market participants with better ratings by boosting competition is difficult because of high market entry barriers, which are increased even further by the widespread regulatory use of ratings, and a problematic "issuer pays" business model.

\section{The dependence on CRAs}

Given low rating quality, it has also been proposed to increase oversight and supervision of CRAs, if not to transform the practice of credit rating into a public service (Paudyn 2011). However, a more active engagement of governments is inopportune for a couple of reasons. First, the adoption of a resource-intensive task is not very enticing for states plagued by austerity, because the regulation of market risk is immensely complex and requires significant resources from public regulators. Second, increased oversight is unattractive, because the supervisor can easily be "held responsible for the ratings" (Eijffinger 2012, 915). In fact, the outsourcing of delicate tasks and decisions represents a typical blame-avoidance strategy (Hinterleitner 2015; Hinterleitner and Sager 2015). Whenever CRAs err, a scapegoat is easily available. 
Taken together, this analysis of regulatory interventions informed by the rationalist optic not only reveals that regulators depend on CRAs. It also suggests that it is unlikely that more transparency and competition can improve the quality of credit ratings and thereby provide market participants with more adequate information. The only straightforward solution that results from the preceding analysis is to limit the regulatory use of ratings to a reasonable extent. However, this solution alone cannot guarantee that CRAs issue high-quality ratings and that market participants can better understand those ratings. In the next section, we discuss whether the sociological optic may complement the rationalist optic to improve the quality of credit ratings.

\section{Why credit ratings hide uncertainty}

Credit ratings in their current form are essentially based on a rationalist optic, since they convey that all uncertainties and risks relevant to the creditworthiness of an entity can be condensed into a single representative grade that states the risk of default (Carruthers 2013). By transforming uncertainties into default risks, uncertainties are "absorbed," suggesting that they have been eliminated. Uncertainty absorption "takes place when inferences are drawn from a body of evidence and the inferences, instead of the evidence itself, are then communicated" (March and Simon 1993, 186). This process of uncertainty absorption removes assumptions, discretion and ambiguity, producing a rating that appears much more robust and authoritative than it actually is (Espeland and Stevens 2008). From this perspective, ratings are not uncertainty-reducing devices, but rather "uncertainty-downplay- ing comfort certi-ficates" (Power 1997).

Market participants may thus neglect uncertainties when consulting a credit rating to form their expectations about an entity's creditworthiness. This is unproblematic in times of well-functioning markets when no one actually wants (and needs) to know the uncertainties hidden behind single ratings. However, when sudden and unexpected events unsettle market participants, single ratings lose their uncertainty-downplaying qualities and force market participants to take all those re-emerging uncertainties into account and adapt their expectations accordingly. The rapid downgrades of previously top-rated subprime products in the 2008 crisis demonstrate how single-grade ratings suddenly lost their sedative effect and compelled market participants to radically adapt their expectations about creditworthiness, leading to an abrupt change in market behavior.

The sociological optic thus reveals that CRAs do not manage uncertainties by transforming them into risks, but only temporarily hide them behind a "simple set of comparative symbols" (Bruner and Abdelal 2005, 210). The focus on uncertainty and its role in expectation formation deepens the understanding of the problematic practice of credit rating, because it elucidates the conventional usage of ratings and the negative potential for confidence development between market participants. This finding contradicts a rationalist optic, which suggests that uncertainties can be transformed into calculable risks and are thus not of much relevance for the formation of expectations (Best 2008).

If combined, the rationalist and the sociological optic illustrate how the authoritativeness of ratings brought about 
by their regulatory use and the uncertainty-downplaying presentation of ratings in single-grade form can develop negative potential in combination with uncertainty. If ratings were not overly authoritative, the single-grade presentation would be unproblematic, since ratings would only represent "opinions" (in Moody's terminology). Accordingly, market participants would not attach too much importance to the ratings of CRAs. Similarly, if ratings adequately depicted both risks and uncertainties, their authoritativeness would be less problematic. In conjunction, however, a state of uncertainty, the presentation of ratings in single-grade form, and the authoritativeness of ratings develop negative potential for confidence development between market participants (see Figure $1)$.

\section{Policy implications}

The preceding analysis suggests that two issues must be targeted. On one hand, the rationalist optic suggests to target the authoritativeness of ratings on the system level by limiting their regulatory use. On the other hand, the sociological optic suggests stabilizing uncertainties by addressing the uncertainty-ignoring conventional usage of credit ratings on the micro-level.

The system-level: reducing the authori-tativeness of ratings

Regulatory interventions must make sure that market participants do not solely rely on the estimates of CRAs to assess the financial and economic constitu-

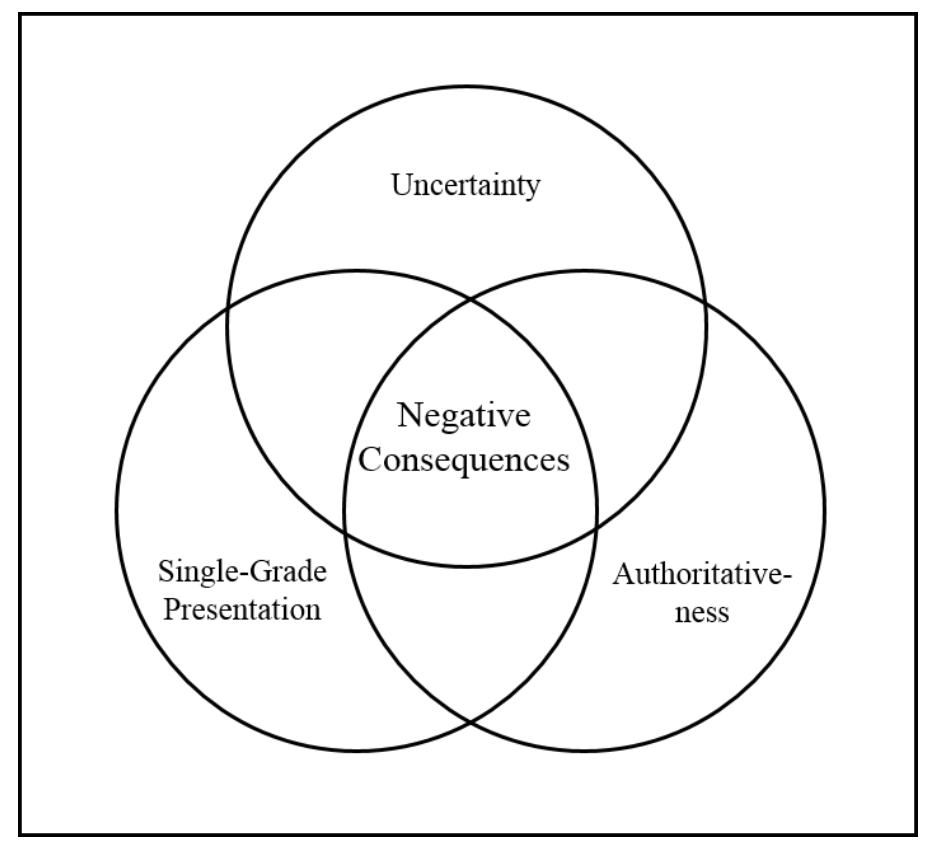

Figure 1: Prerequisites for the negative potential of credit ratings 
tion of trading partners. In order to achieve this purpose, it has been proposed to limit the regulatory use of ratings to a reasonable extent and make capital markets more resilient to occasional "shocks" coming from CRAs' ratings. An example that considers both aspects can be found in current reform efforts by the Basel Committee on Banking Supervision (BCBS), influenced by a macro-prudential approach to regulation. In the BCBS's Basel III agreements, a package of reforms intended to make banking organizations more resilient by augmenting both the quality and quantity of their capital, the BCBS attempts to limit the regulatory use of ratings (BCBS 2010). Basel III proposes alternatives to credit ratings for banks to determine their credit-risk exposure. Accordingly, in the case of an erroneous rating, it would be more unlikely that banks, which use this rating for the calculation of their capital requirements for credit risk, suddenly lack capital to cover the latter. In order to make capital markets more resilient to occasional "shocks" coming from CRAs' ratings, the reform package includes higher capital ratios as well as additional countercyclical capital conservation buffers for unexpected losses. Higher capital ratios make banks more resilient for situations in which sudden rating changes force them to significantly readjust their expectations ${ }^{6}$.

The micro-level: disclosing uncertainties properly

A limited regulatory use of ratings needs to be flanked by interventions tar- geting the conventional usage of ratings as "uncertainty-downplaying comfort certificates." Regulators need to help market participants change their belief that a credit rating is not only an authoritative measure for credit risk, but that the rating also represents a picture for uncertainty. This can be achieved by ensuring that the uncertainties and risks contained in a single-grade rating are not "absorbed" (and thereby hidden), but disclosed properly. This would support market participants to better consider the uncertainties that are relevant for an entity's creditworthiness when they form their expectations.

A useful proposal is that of establishing a "bifurcation" in the presentation of qualitative and quantitative aspects of a credit rating. In addition to the traditional rating containing qualitative data and interpretations, a rating that is solely based on quantitative data could be published (Bruner and Abdelal 2005). By comparing both ratings, market participants could better assess the degree of subjectivity and judgment contained in the rating. Moreover, CRAs may be obliged to publish an additional fan chart that sheds light on the confidence limits of their forecasts (Goodhart 2010).

Even further go credit risk assessments presented in the style of a sophisticated weather forecast: modern forecasts give additional details on general weather patterns, rainfall probabilities, and wind speeds. In a similar vein, CRAs could be brought to publish additional information on single-grade credit ratings, encompassing confidence intervals of their

\footnotetext{
${ }^{6}$ Reform efforts going in the same direction but lacking impetus have been proposed and advanced on a larger scale by the Financial Stabilities Board (FSB 2012).
} 
estimates, the influence of macro-level economic and political phenomena on the default probability, the developments that were especially difficult to judge, what kind of non-quantifiable developments (i.e. uncertainties) entered the rating, etc. Such ratings would not make the impression of an absolute and definite fact, but of an estimate tainted with uncertainties and judgments; more subjective opinion than objective truth. This does not mean to simply overwhelm market participants with more information they may not be able to handle, but to give a more realistic impression of the subjectivity of ratings. Market participants would interpret ratings with greater caution, get a better grasp on the contained uncertainties, and could integrate them into their expectation formation from the outset ${ }^{7}$.

Finally, a positive side effect of properly disclosing relevant uncertainties would be that reputation-based competition between CRAs is enhanced, since their qualitative assessments of uncertainties could be evaluated retrospectively. As noted earlier, competition between CRAs is hard to establish because of high market entry barriers and a problematic "issuer pays" business model. But the fact that the current oligopolistic market structure leads to a significant herd mentality characterized by high correlations between ratings also stems from the categorical presentation of ratings in single-grade form. The single-grade form does not allow for nuances to be adequately expressed and thus precludes an area of judgment where CRAs could compete. Competition in properly picturing uncertainties would grant authoritativeness in the assessment of risks and uncertainties not by regulatory decree, but for a competence otherwise hidden by the single grade.

\section{Discussion}

$s$ the previous analysis has re-
vealed, an approach that analyzes
the current practice of credit rating from a sociological point of view leads to a better understanding of the conventional usage of credit ratings and the negative consequences for expectation formation that emanate therefrom. If one exclusively adopts the rationalist optic, which assumes that uncertainties do not play a significant role in the expectation formation of market participants, because they can be transformed into calculable risks, one cannot reveal and properly understand the problems associated with uncertainty-downplaying single-grade credit ratings. Moreover, by considering the role of uncertainty in actor's expectation formation, the sociological optic applied here contributes to finding solutions where regulatory interventions such as more transparency or increased market competition do not suffice to tackle the issue or simply cannot be put into practice. We can thus conclude that in the above case, the sociological optic has proven useful by providing a deeper understanding of the regulatory problem.

Moreover, the case of CRAs demonstrates that the sociological optic complements, rather than replaces, regulatory interventions informed by a ratio-

\footnotetext{
7 These proposals should not be conflated with qualitative information currently published by CRAs, where more nuanced statements can sometimes be found but uncertainties are only disclosed if deemed relevant by CRAs.
} 
nalist optic. As stated above, in complex international capital markets, CRAs are needed for their information processing capacities and the management of credit risks-and political realities speak against more active states in this field. However, the management of credit risks does not depend on absorbing uncertainties. Instead, uncertainties can be treated as "residuals" that need to be properly disclosed. As emphasized here, it is the application of both optics that allows for a balanced regulatory approach-an approach that considers both the authoritativeness of ratings brought about by their regulatory use and their uncertainty-downplaying qualities.

What about the wider applicability of the sociological optic to concrete regulatory problems? The case makes clear that this optic does not provide a panacea-like new kind of regulation or intervention strategy for public authorities. Some ideas are already implicitly present in current debates and policies, but can profit from being discussed explicitly from a sociological point of view. For instance, by controlling price stability and applying the instrument of "forward guidance"-based on the idea that central banks provide detailed information on their expected future behavior-central banks try to manage the expectations of market participants. The same idea can be observed in current accounting reform, targeting excesses in "mark-to-market" accounting practices. Since accounting firms provide information about the financial constitution of an economic entity, it is in the interest of regulators to ensure that accountants estimate their entity's financial situation as accurately as possible. However, International Financial Reporting Standards and U.S. Generally Accepted Accounting Principles have seen a marked shift to "fair" (i.e., market price) value accounting in recent years. Fair-value accounting assumes that the assets, liabilities, and equity of firms can at all times be accurately priced, i.e., all uncertainties and risks contained in these positions can be transformed into single, supposedly "correct" prices. This can be hazardous when unexpected changes in market prices resulting from abrupt changes of expectations force firms to quickly adjust their balance sheets (Best 2010). Hence, fair-value accounting practices are a potential source of uncertainty for market participants who form their expectations about an entities financial well-being. These examples suggest that an approach that explicitly analyses regulatory issues from a sociological perspective can be fruitfully applied to other regulatory problems. By applying a sociological optic to real-world puzzles in the realm of economic and financial regulation and governance, future research can further refine this optic and create generic knowledge about the conditions under which it proves particularly useful (George and Bennett 2005, chapter 12).

\section{Conclusion}



ince the 2008 crisis, regulatory approaches and principles have increasingly been drawn into question. This paper has retraced how the rationalist optic on markets, going back to a paradigm shift associated with the neoliberal turn, has recently been challenged by an increasingly popular sociological optic. Borrowing from the Keynesian paradigm, this optic stresses the fundamental difference between risk and uncertainty, the role of uncertainty in expectation formation, and the importance of social conventions for 
stabilizing uncertainty and structuring human interaction. Subsequently, the paper has applied both optics to a concrete regulatory problem, namely the role of CRAs and their ratings in international capital markets.

In conclusion, an approach that explicitly targets expectation formation under uncertainty can help to analyze tricky regulatory problems and complement conventional regulatory interventions based on a rationalist optic. The sociological optic does not only offer "a useful analytical lens to complement and enrich rationalist explanations and thus help [s] us understand the world of risk and uncertainty that we all inhabit" (Nelson and Katzenstein 2014, 364). It also offers practical advice to tackle actual regulatory problems.

\section{References}

Akerlof, George A. 1970. "The Market for 'Lemons': Quality Uncertainty and the Market Mechanism." Quarterly Journal of Economics 84 (3): 488-500.

Amable, Bruno et al. 2010. "Crisis in the Regulation Regime-A New Paradigm?" Socio-Economic Review 8: 537-541.

Baker, Andrew. 2013. "The Gradual Transformation? The Incremental Dynamics of Macroprudential Regu-lation." Regulation \& Governance 7: 417-434.

Baker, Scott R., Nicholas Bloom, and Steven J. Davis. 2013. Measuring Economic Policy Uncertainty. http://www. policyuncertainty.com/research.html (accessed August 1, 2015).
Basel Committee on Banking Supervision (BCBS). 2010. Basel III: International Framework for Liquidity Risk Measurement, Standards and Monitoring. http:// www.bis.org/publ/bcbs188.htm (accessed August 1, 2015).

Battalio, Robert, and Paul Schultz. 2011. "Regulatory Uncertainty and Market Liquidity: The 2008 Short Sale Ban's Impact on Equity Option Markets." The Journal of Finance, 66 (6): 2013-2053.

Beckert, Jens. 2013. "Capitalism as a System of Expectations: Toward a Sociological Microfoundation of Political Economy." Politics \& Society 41 (3): 323-350.

Best, Jacqueline. 2008. "Ambiguity, Uncertainty, and Risk: Rethinking Indeterminacy." International Political Sociology 2: 355-374.

Best, Jacqueline. 2010. “The Limits of Financial Risk Management: Or What We Didn't Learn from the Asian Crisis." New Political Economy 15 (1): 29-49.

Biggart, Nicole Woolsey, and Thomas D. Beamish. 2003. “The Economic Sociology of Conventions: Habit, Custom, Practice, and Routine in Market Order." Annual Review of Sociology 29: 443-464.

Black, Julia. 2013a. "Seeing, Knowing, and Regulating Financial Markets: Moving the Cognitive Framework from the Economic to the Social." LSE Law, Society and Economy Working Papers 24: 1-47.

Black, Julia. 2013b. "Reconceiving Financial Markets-From the Economic to the Social." Journal of Corporate Law Studies 13 (2): 401-442. 
Blyth, Mark. 2003. "The Political Power of Financial Ideas: Transparency, Risk, and Distribution in Global Finance." In Monetary Orders: Ambiguous Economics, Ubiquitous Politics, ed. Jonathan Kirshner. Ithaca, NY: Cornell University Press, 239259.

Blyth, Mark. 2006. "Great Punctuations: Prediction, Randomness, and the Evolution of Comparative Political Science." American Political Science Review 100 (4): 493-498.

Bolton, Patrick, Xavier Freixas, and Joel Shapiro. 2012. "The Credit Ratings Game." The Journal of Finance 67 (1): 85-112.

Braithwaite, John. 2008. Regulatory Capitalism: How It Works, Ideas for Making It Work Better. Cheltenham: Edward Elgar Publishing Limited.

Bruner, Christopher M., and Rawi Abdelal. 2005. "To Judge Leviathan: Sovereign Credit Ratings, National Law, and the World Economy." Journal of Public Policy 25 (2): 191-217.

Cantor, Richard, and Frank Packer. 1996. "Determinants and Impacts of Sovereign Credit Ratings." Federal Reserve Bank of New York Economic Policy Review 2 (2): 37-53.

Carruthers, Bruce G. 2013. "From Uncertainty toward Risk: the Case of Credit Ratings." Socio-Economic Review 11 (3): 525-551.

Carruthers, Bruce G., and Jeong-Chul Kim. 2011. "The sociology of finance." Annual Review of Sociology 37: 239-259.
Castles, Frances G., Stephan Leibfried, Jane Lewis, Herbert Obinger, and Christopher Pierson. 2010. "Introduction." In The Oxford Handbook of the Welfare State, eds. Frances G. Castles, Stephan Leibfried, Jane Lewis, Herbert Obinger, and Christopher Pierson. Oxford: Oxford University Press, 1-18.

Dequech, David. 2006. "The New Institutional Economics and the Behaviour under Uncertainty." Journal of Economic Behavior and Organization 59: 109-131.

Eijffinger, Sylvester C.W. 2012. "Rating Agencies: Role and Influence of Their Sovereign Credit Risk Assessment in the Eurozone." Journal of Common Market Studies 50 (6): 912-921.

Espeland, Wendy Nelson, and Mitchell L. Stevens. 2008. "Commensuration as a Social Process." Annual Review of Sociology 24: 313-343.

Fama, Eugene F. 1970. "Efficient Capital Markets: A Review of Theory and Empirical Work." The Journal of Finance 25 (2): 383-417.

FSB (Financial Stability Board). 2012. Roadmap for Reducing Reliance on CRA Ratings. http://www.financialstabilityboard .org/2012/11/r_121105b/ (accessed August 1, 2015).

Gaillard, Norbert. 2011. A Century of Sovereign Ratings. Berlin: Springer.

George, Alexander L., and Andrew Bennett. 2005. Case Studies and Theory Development in the Social Sciences. Cambridge, MA: MIT Press. 
Goodhart, Charles A.E. 2010. "How, If At All, Should Credit Ratings Agencies (CRAs) Be Regulated?" In Time for a Visible Hand: Lessons from the 2008 World Financial Crisis, eds. Stephany Griffith-Jones, José Antonio Ocampo, and Joseph Stiglitz. Oxford: Oxford University Press, 164-181.

Hall, Peter A. 1993. "Policy Paradigms, Social Learning, and the State: The Case of Economic Policymaking in Britain." Comparative Politics 25 (3): 275-296.

Hinterleitner, Markus. 2015. "Reconciling Perspectives on Blame Avoidance Behaviour." Political Studies Review. Early online: 1-12.

Hinterleitner, Markus, and Fritz Sager. 2015. "Avoiding Blame: A Comprehensive Framework and the Australian Home Insulation Program Fiasco." Policy Studies Journal 43 (1): 139-161.

Hu, Henry T.C. 2012. “Too Complex to Depict? Innovation, Pure Information, and the SEC Disclosure Paradigm." Texas Law Review 90 (7): 1601-1715.

Hutter, Bridget M., ed. 2010. Anticipating Risks and Organising Risk Regulation. Cambridge: Cambridge University Press.

Iyengar, Shreekant. 2010. "Are Sovereign Credit Ratings Objective and Transparent?" The IUP Journal of Financial Economics 8 (3): 7-22.

Julio, Brandon, and Youngsuk Yook. 2012. "Political Uncertainty and Corporate Investment Cycles." The Journal of Finance 67 (1): 45-83.
Kerwer, Dieter. 2005. "Holding Global Regulators Accountable: The Case of Credit Rating Agencies." Governance 18 (3): 453-475.

Keynes, John M. 1936. The General Theory of Employment, Interest, and Money. New York: Harcourt, Brace \& World.

Keynes, John M. 1937. "The General Theory of Employment.” The Quarterly Journal of Economics 51 (2): 209-223.

Kingsley, Allison F., Richard G. Vanden Bergh, and Jean-Philippe Bonardi. 2012. "Political Markets and Regulatory Uncertainty: Insights and Implications for Integrated Strategy." Academy of Management Perspectives 26 (3): 52-67.

Knight, Frank. 2006 [1921]. Risk, Uncertainty, and Profit. New York: Cosimo.

Levi-Faur, David. 2011. "The Odyssey of the Regulatory State: Episode One: The Rescue of the Welfare State." Jerusalem Papers in Regulation \& Governance Working Paper No. 39.

Levi-Faur, David, and Christine Parker. 2010. "Three Narratives of the Global Economic Crisis." Socio-Economic Review 8: 547-553.

Lodge, Martin, and Kai Wegrich. 2010. "Letter to the Editor of Public Administration Review in Response to a Recent Symposium on Financial Regulatory Reform." Public Administration Review 70 (2): 336341.

Majone, Giandomenico. 1997. "From the Positive to the Regulatory State." Journal of Public Policy 17 (2): 139-167. 
March, James G. 1994. A Primer on Decision Making: how Decisions Happen. New York: Free Press.

March, James G., and Herbert Simon. 1993. Organizations. New York: Wiley \& Sons.

Moloney, Niamh. 2010. "Financial Services and Markets." In The Oxford Handbook of Regulation, eds. Robert Baldwin, Martin Cave, and Martin Lodge. New York: Oxford University Press, 437-461.

Moody's. 2009. Rating Symbols \& Definitions. https://www.moodys.com/ (accessed June 1, 2015).

Nelson, Stephen. C., and Peter J. Katzenstein. 2014. "Uncertainty, Risk, and the Financial Crisis of 2008." International Organization 68 (2): 361-392.

OECD. 2008. Introductory Handbook for Undertaking Regulatory Impact Analysis (RIA). http://www.oecd.org/gov/regulatory-policy/ria.htm (accessed August 1, 2015).

Pagano, Marco, and Paolo Volpin. 2010. "Credit Rating Failures and Policy Options." Economic Policy 25 (62): 401-431.

Partnoy, Frank. 2006. "How and Why Credit Rating Agencies are Not Like Other Gatekeepers." In Financial Gatekeepers: Can They Protect Investors, eds. Yasuyuki Fuchita, and Robert. E. Litan. Washington, DC: Brookings Institution Press, 59-102.

Partnoy, Frank. 2009. "Overdependence on Credit Ratings was a Primary Cause of the Crisis." Research Paper 9 (15). San Diego, CA: University of San Diego.
Paudyn, Bartholomew. 2011. "Misguided Ventures: A Quasi-Public European Union Credit Rating Agency." Intereconomics 46 (5): 259-262.

Power, Michael. 1997. The Audit Society: Rituals of Verification. Oxford: Oxford University Press.

Róna-Tas, Ákos, and Stefanie Hiß. 2010. "Consumer and Corporate Credit Ratings and the Subprime Crisis in the U.S. with Some Lessons for Germany." In Consumer Loans and the Role of the Credit Bureaus in Europe, ed. Hans-Wolfgang Micklitz. EUI Working Papers RSCAS 2010/44, 5-28.

Sewell, William H. 2008. "The Temporalities of Capitalism." Socio-Economic Review 6 (3): 517-537.

Sinclair, Timothy J. 1994. "Credit Rating Processes as Regulatory Mechanisms of Governance in the Emerging World Order." Review of International Political Economy 1 (1): 133-159.

Sinclair, Timothy J. 2001. "The Infrastructure of Global Governance: Quasi-Regulatory Mechanisms and the New Global Finance." Global Governance 7 (4): 441-451.

Sinclair, Timothy J. 2005. The New Masters of Capital. Ithaca, NY: Cornell University Press.

Tonkiss, Fran. 2009. "Trust, Confidence and the Economic Crisis." Intereconomics 44 (4): 196-202.

Trampusch, Christine. 2013. "Why Preferences and Institutions Change: A Systematic Process Analysis of Credit Rating 
in Germany." European Journal of Political Research 53 (2): 328-344.

Vibert, Frank. 2011. "Regulation in an Age of Austerity: Reframing International Regulatory Policies." LSE Global Governance Working Papers 3.

Vogel, Steven. 2010. "A Socio-Economic Perspective on the Financial Crisis." Socio-Economic Review 8: 553-557.

White, Lawrence J. 2002. "The Credit Rating Industry: An Industrial Organization Analysis." In Ratings, Rating Agencies and the Global Financial System, eds. Richard M. Levich, Giovanni Majnoni, and Carmen M. Reinhart. Boston: Kluwer, 41-63.

White, Lawrence J. 2010. "Markets: The Credit Rating Agencies." Journal of Economic Perspectives 24 (2): 211-226.

Yeung, Karen. 2010. "The Regulatory State." In The Oxford Handbook of Regulation, eds. R. Baldwin, M. Cave, and M. Lodge. New York: Oxford University Press, 64-83. 